\title{
Compsobuthus matthiesseni sting from Bazoft: A case report
}

\author{
Rouhullah Dehghani $^{\circledR}$, Kobra Taji' ${ }^{1}$, Amrollah Mahmoudi', Masoomeh Varzandeh2*(D) \\ 'Social Determinants of Health (SDH) Research Center and Department of Environment Health, Kashan University of \\ Medical Sciences, Kashan, Iran \\ ${ }^{2}$ Department of Clinical toxicology and Poisoning, Afzalipour hospital, Kerman University of Medical Sciences, \\ Kerman, Iran
}

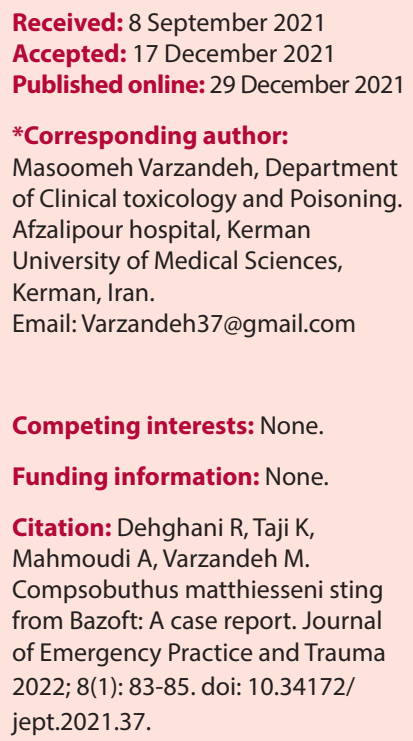

\begin{abstract}
Objective: A Scorpion sting is one of the most important health and medical problems in most parts of Iran.

Case Presentation: This case report occurred in Chaharmahal Bakhtiari province of Bazoft city. The injured person was a 48-year-old woman, weighing about $69 \mathrm{~kg}$. Two documentary filmmakers were on their way to work and suddenly one of them felt pain caused by a sting in the thigh area of her lower limb. The patient was referred to the medical center with the 'scorpion' sample, where she was examined by a doctor. The doctor prescribed some medicine for the patient. The pain from the sting lasted for about three hours. The patient recovered after taking the medication and received counseling three days after the sting. A photo of the dorsal and ventral surface of the scorpion specimen was sent to the animal identification specialist along with the size and color record. Scorpion specimen with a size of $4 \mathrm{~cm}$ was identified as Compsobuthus matthiesseni.

Conclusion: According to the findings of this report, the clinical signs of $C$. matthiesseni sting are mild in the injured person and comparable to the stings of yellow bees Vespa germania. There is local pain two to three hours after the sting. Other systemic clinical manifestations can improve after a maximum of 2 to 3 days.

Keywords: Scorpion sting, Compsobuthus matthiesseni, Buthidae, Bazoft, Iran
\end{abstract}

\section{Introduction}

Scorpion sting is one of the most important health and medical problems in most parts of Iran, especially in the south $(1,2)$. Most causes of scorpion stings in Iran belong to the Buthidae species which are present all over the country and among them there are some species with medical importance. One of the prominent features of the species of this family is the venom with neurotoxic properties $(3,4)$.

There are reports from scorpion stings in all provinces of Iran such as Khuzestan, Hormozgan, Sistan and Baluchestan, Fars, Ilam, Bushehr, Kerman, Kohkiluyeh and Boyer-Ahmad, Kermanshah, Isfahan, Khorasan, West Azerbaijan, Kurdistan, Tehran, Qom, East Azerbaijan and Yazd, Chaharmahal and Bakhtiari, Ardabil, Markazi, Gilan, Lorestan, Semnan, Mazandaran and Golestan (5).

Compsobuthus matthiesseni scorpion is one of the species which belongs to the Buthidae family with a clear yellow color and a length of 3 to $4.5 \mathrm{~cm}$. This species belongs to the Buthidae family and the genus Compsobuthus. So far, 7 species of this genus have been reported in Iran.
In Khuzestan, C. matthiesseni scorpion has been introduced as one of the main causes of stings. Former oral reports of villagers and nomads of Khuzestan about the sting of this scorpion and the bloody urine caused by it have been quoted (6). However, no case report has been documented so far.

Of the Compsobuthus genus, species of C. persicus has been reported as one of the causes of sting with a relatively high frequency in Hormozgan, Bushehr and Fars provinces.

Local pain has been the most important chief complaint of patients due to sting with this species. After that, vertigo is the most common complaint.

Based on the para clinic data of patients with this scorpion sting none of them had hematuria and did not receive any anti-venom and Laboratory coagulation and complete blood count tests were normal (7).

Diagnosis of the cause of any sting, in any geographical area of Iran, based on the study of morphological parameters of the sample sting agent with the patient is very valuable and should be identified by experts. 
Owing to the fact that scorpion sting is one of the health problems and due to the importance of the identification of sting species in different parts of Iran in the treatment of injuries, the sting report of this case from Bazoft area of Chaharmahal Bakhtiari province can clarify the role of this species in the severity of envenomation in a more accurate and specific way, which is always accompanied by mild clinical manifestations.

\section{Case Presentation}

This report is about a person who was stung while she was walking. The incident occurred in Chaharmahal and Bakhtiari province of Bazoft city, Telord town, on June 4, 2020.

The injured person was a 48-year-old woman, weighing about $69 \mathrm{~kg}$. The documentary filmmaker was walking to work who suddenly felt pain caused by a sting in the thigh area of her lower limbs.

The woman felt burning and pain in her thigh like a bee sting; she squeezed the sting site to make sure she has removed the sting agent.

Then she inspected her pants in the right place and observed the cause of the sting that fell out from inside the pants. The patient went to the castle lawn health house with a sample and there she was examined by the doctor of the center. After examination and seeing the sample, the doctor prescribed hydrocortisone ampoule, diphenhydramine syrup and cetirizine tablets. The ampoule was injected immediately and the rest of the medication was used as instructed. The patient did not receive anti-scorpion anti-venom.

The pain from the sting lasted for about three hours and then it gradually diminished and completely disappeared. But the patient had dizziness, nausea and lethargy for two days after the sting and her body could not do the necessary activities.

The patient's symptoms improved after taking the medication and counseling three days after the sting. Photographs of the dorsal surface (Figure 1) and abdomen (Figure 2) of the sample along with recording the size and color were sent to the animal identification specialist. The scorpion with a size of $4 \mathrm{~cm}$ was identified as C. matthiesseni.

\section{Discussion}

The results of this study showed that Chaharmahal and Bakhtiari province is an area with a high distribution of this species (6). In Khuzestan province, the scorpion C. matthiesseni included $20.6 \%$ of the stings and was introduced as one of the main causes of stings in this province.

Compsobuthus matthiesseni belongs to the Buthidae family with a clear yellow color and a size of 3 to $4.5 \mathrm{~cm}$. It lives in hot and humid places in the crevices of rocks and tree bark (8).

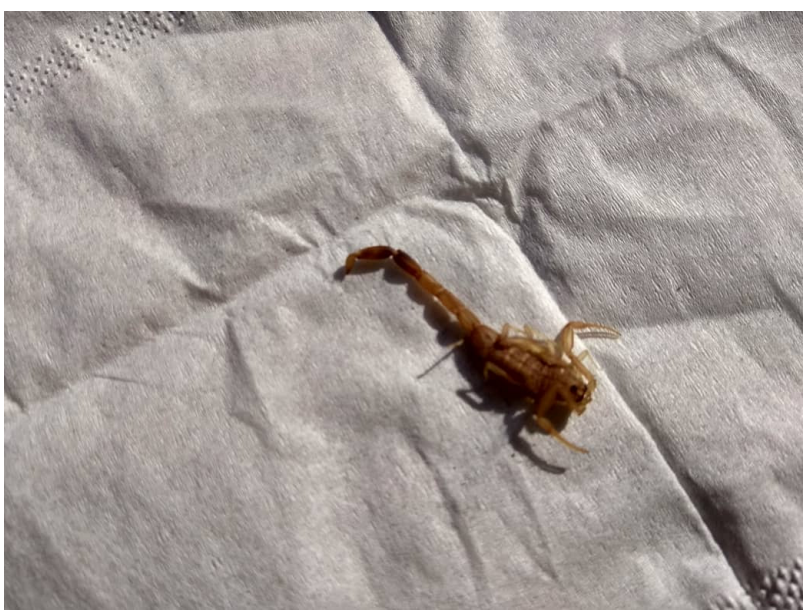

Figure 1. The dorsal surface of Compsobuthus matthiesseni.

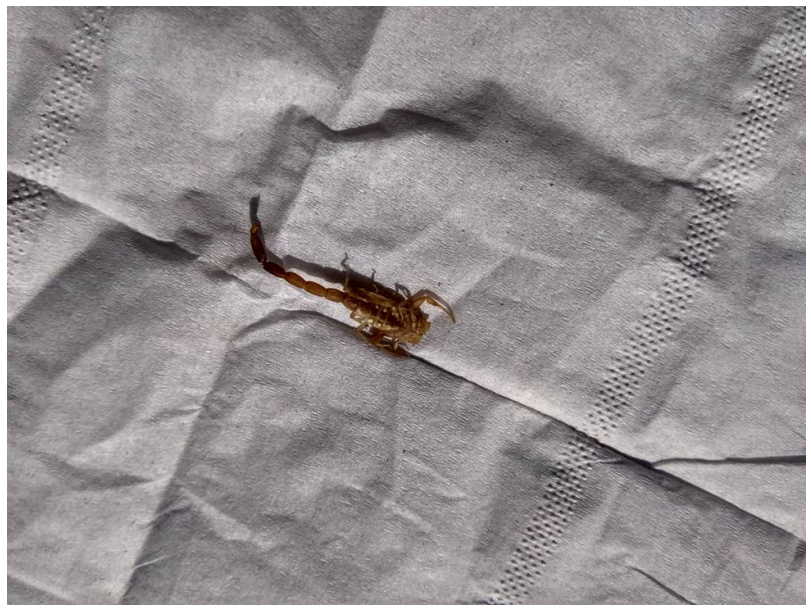

Figure 2. Ventral surface of Compsobuthus matthiesseni.

This study showed that C. matthiesseni stings do not have dangerous clinical complications, except for the local pain at the site of the sting in the first 2 to 3 hours. The sting does not cause an acute problem, does not cause blood problems and does not change the biochemical parameters of the blood. The results of this report are consistent with the studies of other researchers.

According to some relatively old reports of villagers and nomads in Khuzestan province who were stung by $C$. matthiesseni scorpion, blood was reported in their urine. Thus, villagers were afraid of approaching the scorpion. This finding was not consistent with the results of our study $(9,10)$.

Due to the fact that there are many different species of scorpions in Iran, the stings of these arthropods are probably as diverse as the frequency, but the cases of stings usually depend on the frequency and abundance of scorpions in areas of human activity.

Research on the distribution and frequency of scorpions in each area also shows the status of human scorpion stings. It should be noted that the behavioral, biological and ecological differences of these animals are effective in the amount of contact with humans $(5,8)$. 
The important point in treatment is recognizing, specifically, the sting of each scorpion, because by recognizing the side effects of different species, the specific treatment method for each scorpion can be used. It is important to mention that it is not possible to use the same prescription and the same treatment instructions for the treatment of all species.

Physicians can be of great help in treating patients who have a permanent presence in the area and have collected and studied the initial information about different species stings of these arthropods and their clinical symptoms. In addition to recognizing the local and systemic clinical manifestations of scorpion stings, physicians should be familiar with the morphology and characteristics of dangerous and harmless scorpions in the area in order to choose the appropriate treatment protocol quickly and in a timely manner (5,8,11-13).

\section{Conclusion}

According to the findings of this report, the clinical signs of Compsobuthus matthiesseni sting are mild in the injured person and comparable to the sting of the yellow bee Vespa germanica. Local pain is considered as the most common symptom of a sting in the injured person and can improve with supportive therapies 2 to 3 hours after the sting and of course, in people without the underlying disease, they disappear completely faster.

It seems that this species does not need anti-venom. However, a more precise statement, especially in the case of children, depends on the examination of more cases of the desired stings.

\section{Authors' contributions}

All authors contributed in data collection and writing of the paper and approved final version.

\section{Ethical issues}

Informed consent was obtained from the patient for publication of this report.

\section{References}

1. Kassiri H, Kassiri A, Kasiri E, Safarpor S, Lotfi M. A hospital-based study on scorpionism in Khorram-Shahr county, southwestern Iran. Asian J Epidemiol 2014; 7(2): 28-35. doi: 10.3923/aje.2014.28.35.

2. Nazari M, Hajizadeh MA. A faunistic study on scorpions and the epidemiology of scorpionism in Bam, southeast of Iran. Glob J Health Sci 2017; 9(2): 177-83. doi: 10.5539/ gjhs.v9n2p177.

3. Kassiri H, Kassiri A, Sharififard M, Shojaee S, Lotfi M, Kasiri E. Scorpion envenomation study in Behbahan county, southwest Iran. J Coast Life Med 2014; 2(5): 41620. doi: 10.12980/jclm.2.201414j24.

4. Nejati J, Mozafari E, Saghafipour A, Kiyani M. Scorpion fauna and epidemiological aspects of scorpionism in southeastern Iran. Asian Pac J Trop Biomed 2014; 4(Suppl 1): S217-21. doi: 10.12980/apjtb.4.2014c1323.

5. Dehghani R, Kamiabi F, Mohammadi M. Scorpionism by Hemiscorpius spp. in Iran: a review. J Venom Anim Toxins Incl Trop Dis 2018; 24: 8. doi: 10.1186/s40409-018-0145-Z.

6. Barahoei H, Navidpour S, Aliabadian M, Siahsarvie R, Mirshamsi O. Scorpions of Iran (Arachnida: Scorpiones): annotated checklist, DELTA database and identification key. Journal of Insect Biodiversity and Systematics 2020; 6(4): 375-474.

7. Shahi M, Sanaei-Zadeh H. Clinical manifestations of Compsobuthus persicus scorpion envenomation in southern Iran. Iran J Toxicol 2020; 14(3): 171-8. doi: 10.32598/ ijt.14.3.415.2.

8. Dehghani R, Dinparast N, Shahbazzadeh D, Bigdelli S. Introducing Compsobuthus matthiesseni (Birula, 1905) scorpion as one of the major stinging scorpions in Khuzestan, Iran. Toxicon 2009; 54(3): 272-5. doi: 10.1016/j. toxicon.2009.04.011.

9. Farzanpey R. Scorpion Recognition. Tehran, Iran: Publications of University Press Center; 1987. p. 231. [Persian].

10. Farzanpey R. Scorpion sting and the fallowing of it. Pajouhesh va Sazandegi 1994; 25(3): 123-5. [Persian].

11. Mohammadi Bavani M, Rafinejad J, Hanafi-Bojd AA, Oshaghi MA, Navidpour S, Dabiri F, et al. Spatial distribution of medically important scorpions in north west of Iran. J Arthropod Borne Dis 2017; 11(3): 371-82.

12. Jalali A, Rahim F. Epidemiological review of scorpion envenomation in iran. Iran J Pharm Res 2014; 13(3): 743 56.

13. Radmanesh M. Clinical study of Hemiscorpius lepturus in Iran. J Trop Med Hyg 1990; 93(5): 327-32. 